\title{
Hyperperfusion syndrome following endovascular cerebral revascularization
}

\author{
A review \\ Ricky Medel, M.D., ${ }^{1}$ R. Webster Crowley, M.D., ${ }^{1}$ And Aaron S. Dumont, M.D. ${ }^{1,2}$ \\ Departments of ${ }^{\prime}$ Neurological Surgery and ${ }^{2}$ Radiology, University of Virginia Health System, \\ Charlottesville, Virginia
}

\begin{abstract}
Endovascular cerebral revascularization is becoming a frequently used alternative to surgery for the treatment of atherosclerotic disease, especially in the intracranial circulation where options are limited. Recent literature regarding the equivalent efficacy of carotid artery stenting and carotid endarterectomy in certain patient populations, as well as the recognition of the significant risk for recurrent stroke posed by intracranial lesions, will only serve to amplify this trend. Hyperperfusion syndrome has been well documented in the setting of carotid endarterectomy; however, a paucity of literature exists regarding the incidence, pathophysiology, and management as it relates to percutaneous interventions. The purpose of this review is to outline the current state of knowledge, with particular attention to the distinct attributes of endovascular treatment that would be expected to modify the course of hyperperfusion syndrome. (DOI: 10.3171.2009.1.FOCUSO8276)
\end{abstract}

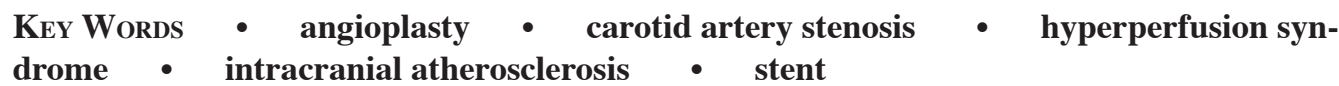

$\mathrm{E}$ NDOVASCULAR cerebral revascularization is being increasingly used as an alternative to surgical intervention, especially in the management of intracranial atherosclerosis. Recent literature revealing a similar efficacy between CAS and CEA in certain populations, as well as the escalating recognition of intracranial lesions as a significant contributor to the incidence of ischemic stroke, has only served to augment this trend..$^{5,12,41}$ Concerning intracranial lesions, treatment was previously limited to medical therapy, including anticoagulation treatment, and the modification of risk factors. However, since the pioneering work of Sundt et al., ${ }^{37}$ endovascular management has become an efficacious alternative.? Furthermore, substantial impetus for persistent evolution exists, as despite the implementation of maximal medical management, stroke recurs with considerable frequency. ${ }^{5,14,15}$ Consequently, the use of endovascular cerebral revascularization has intensified. Unfortunately, as is the case with any procedure, this therapy is not entirely without adverse effects.

In 1978, Spetzler et al. ${ }^{34}$ first described the "normal perfusion pressure breakthrough theory" to describe the precipitous decline observed in a 49-year-old woman following the resection of a large right parietal arterio-

\footnotetext{
Abbreviations used in this paper: $\mathrm{CA}=$ carotid artery; $\mathrm{CAS}=\mathrm{CA}$ stenting; $\mathrm{CBF}=$ cerebral blood flow; $\mathrm{CEA}=$ carotid endarterectomy; HPS = hyperperfusion syndrome; ICH = intracerebral hemorrhage.
}

venous malformation. Despite a technically successful surgery the patient died of cerebral edema and hemorrhage, a phenomenon hypothesized to occur as a result of impaired autoregulation in an area of chronic ischemia. Sundt and colleagues ${ }^{36}$ later provided the first detailed description of HPS following CEA. In their analysis of 1145 patients undergoing CEA, they noted a constellation of delayed-onset symptoms including atypical migrainous phenomena, focal seizures, and ICHs in a minority of patients, with a predilection for those having $>100 \%$ increase in CBF from baseline. As recognition of HPS broadened, ${ }^{3}$ multiple clinical and laboratory investigations were conducted to better elucidate the incidence, treatment, and pathophysiology of reperfusion injury in this setting. $27,28,32,35$ Notwithstanding this, evidence regarding HPS following CAS remains sparse, in addition to the significant void that exists when considering intracranial revascularization. As such, the purpose of this review is to evaluate the current literature with special attention to the distinct attributes of endovascular therapy expected to modify the course of HPS that has previously been outlined for CEA.

\section{Hyperperfusion Syndrome}

Epidemiology and Clinical Presentation

Hyperperfusion injury is estimated to occur in 1.1- 


\section{R. Medel, R. W. Crowley, and A. S. Dumont}

TABLE 1: Incidence of hyperperfusion syndrome following endovascular revascularization of the craniocervical arteries* $^{*}$

\begin{tabular}{|c|c|c|c|c|c|}
\hline Year & Authors & Intervention & No. of Cases & Hyperperfusion & Associated Factors \\
\hline 2000 & Meyers et al. & $\begin{array}{l}\text { craniocervical } \\
\text { PTA/stenting }\end{array}$ & 140 & $5.0 \%$ & \\
\hline 2000 & Morrish et al. & CAS & 102 & $3.9 \% \mathrm{ICH}$ & \\
\hline 2003 & Coutts et al. & CAS & 44 & $6.8 \%$ & \\
\hline 2004 & Abou-Chebl et al. & CAS & 450 & $1.1 \%$ & $\begin{array}{l}\text { severe stenosis; contralat } \\
\text { stenosis; hypertension }\end{array}$ \\
\hline 2004 & Kaku et al. & CAS & 30 & $30 \%$ & age (>75 yrs); CVR $<20 \%$ \\
\hline 2006 & Terada et al. & $\begin{array}{l}\text { intracranial PTA/ } \\
\text { stenting }\end{array}$ & 106 & $2 \%$ & $\begin{array}{l}\text { age }(>70) ; \dagger \text { severe stenosis; } \\
\text { poor collaterals; low perfu- } \\
\text { sion; \& poor reactivity } \ddagger\end{array}$ \\
\hline 2004 & Zaidat et al. & early CAS & 39 & $2 \%$ & \\
\hline 2007 & Abou-Chebl et al. & CAS & 8369 & $\begin{array}{l}\text { BP-controlled group } 0.5 \% \\
\text { noncontrolled group } 1.9 \%\end{array}$ & hypertension \\
\hline 2007 & Ogasawara et al. & CAS & 2898 & $1 \%$ & none (for ICH) \\
\hline 2008 & Miyamoto et al. & early CAS & 10 & $0 \%$ & \\
\hline
\end{tabular}

* $\mathrm{BP}$ = blood pressure; CVR = cerebrovascular reactivity; PTA = percutaneous transluminal angioplasty.

$\uparrow$ None of the variables listed demonstrated statistical significance.

* As assessed by SPECT after an acetazolamide challenge.

I Includes a portion of the patient population in the previously presented data by the same first author.

$6.8 \%$ of patients following endovascular cerebral revascularization, with mortality rates ranging from 3 to $26 \%$ when ICH is present (Table 1)., $, 6,20,27,39$ Although this occurs with similar frequency to that seen following CEA, ${ }^{27}$ several investigators have recognized that for endovascular treatment there often exists a differing postprocedural time course ${ }^{6}$ Consistent with the description by Sundt and colleagues, ${ }^{27}$ the syndrome usually occurs 5 to 7 days following endarterectomy, ${ }^{27,36}$ whereas with CAS it is more likely to occur within the first 24 hours. $2,6,10,17,18,21,23,25,27$, 29,30,33,38,43 Concurrent with these observations, Coutts et al. ${ }^{6}$ have proposed that HPS be divided into 3 categories based on presentation: acute hemorrhage, acute focal ede$\mathrm{ma}$, and delayed-classic presentation. In one of the largest published series containing 4494 patients, Ogasawara and colleagues $^{27}$ found that onset occurred 5.8 days following CEA in contrast to 1.5 days after CAS ( $p<0.0001)$. The authors hypothesized that this variation occurred as a result of 2 factors: 1) a greater incidence of distal emboli and 2) more profound cerebral ischemia with a subsequent increase in the production of reactive oxygen species following stent placement. Concerning distal emboli, this would represent hemorrhagic transformation and not hyperperfusion, but this too remains questionable, as their definition of HPS appropriately excluded patients in whom there was evidence of restricted diffusion on postoperative MR imaging. Regarding increased ischemia, the authors proposed that this occurred in conjunction with transient bradycardia and hypotension due to damage to the carotid baroreceptor, ${ }^{19}$ yet no evidence exists that this is significantly different from that seen with cross-clamping during surgery. Overall, these explanations are insufficient and serve to underscore an underlying variation in the pathophysiology based on the modality of treatment.

\section{Pathophysiology}

Together carbon dioxide and cerebral autoregulation serve to maintain the consistency of cerebral perfusion over a wide range of systemic blood pressures (60-160 $\mathrm{mm} \mathrm{Hg}$ ). ${ }^{16,40}$ While carbon dioxide significantly influences the smaller arteries, it has little effect on the CAs or the circle of Willis, areas where myo- and neurogenic autoregulation dominate. Increases in blood pressure cause stretching of the vascular smooth muscle, resulting in depolarization and subsequent contraction that limits perfusion. Once the pressure exceeds the ability of this mechanism, further vasoconstriction is dependent on the sympathetic innervations of the vascular adventitia. Notably, the vertebrobasilar circulation has a lower density of this adventitial innervation, making it potentially more susceptible to extreme changes in systemic blood pressure..$^{6,40}$

Ischemic conditions have variable effects on the vasculature, which are dependent on the duration of exposure. Acutely, this leads to endothelial changes that initiate leukocyte and platelet adhesion and subsequent activation. This process can lead to irreversible vascular injury within hours, noted by a breakdown of the blood-brain barrier beginning in the venules. Chronically, ischemia causes maximal dilation of the resistance arteries and arterioles, with a consequent decrease in their responsiveness and tonicity. ${ }^{16}$ In addition, the endothelial damage to the microvasculature produced by diabetes and hypertension, 


\section{Hyperperfusion syndrome after endovascular revascularization}

\section{TABLE 2: Risk factors for the development of HPS*}

\author{
patient age $>75$ yrs \\ long-standing hypertension \\ history of prior stroke \\ recent stroke (see Discussion) \\ poor cerebrovascular reserve \\ severe stenosis $(\geq 90 \%)$ \\ contralateral stenosis \\ poor collateralization \\ postprocedural hypertension
}

*Derived from the works of Abou-Chebl and colleagues (2004), Kaku and associates, and Terada and coworkers.

common comorbidities in this patient population, have also been shown to impair myogenic regulation..$^{40}$ Ensuing reperfusion of the affected territory, even under normotension, is marked by a substantial increase in blood flow. In conjunction with capillaries and venules being exposed to unregulated arterial pressure, the generation of reactive oxygen species occurs, further potentiating endothelial damage..$^{35,40}$ The hydrostatic forces lead to the development of edema, and if sufficient vascular injury has occurred, or if the blood pressure is uncontrolled, intracranial hemorrhage ensues.

While the aforementioned may help explain HPS in general, it does little to elucidate a physiological disparity between the 2 procedures that would explain the variant time course. Investigators have evaluated the hemodynamic changes that occur following CAS and CEA, ${ }^{19,24,32}$ but the only significant difference was more frequent and prolonged hypotension over the first 24 hours after CAS. ${ }^{19}$ Other theories include the potential propensity of endovascular therapy to result in a larger ischemic burden as a result of distal emboli, yet this is unlikely as in nearly all of the reported cases authors have described sudden onset without prodromal symptomatology.,6 Nevertheless, a greater incidence of clinically silent ischemia cannot entirely be ruled out. Another potential contributor, at least for the development of $\mathrm{ICH}$, is the routine use of dual antiplatelet therapy following angioplasty and stent therapy. ${ }^{1}$ Consistent with this is the slightly higher rate of $\mathrm{ICH}$ that has been consistently demonstrated following percutaneous intervention. ${ }^{6,23,27}$

\section{Management of HPS}

Risk Factors. Appropriate management begins with preprocedural evaluation to identify those patients at greatest risk (Table 2), as the prevention of HPS is the primary objective given that treatment is largely symptomatic. Risk factors include patient age ( $>75$ years), history of stroke, long-standing hypertension, severe stenosis, contralateral stenosis, and poor collateralization..$^{2,13,40}$ The latter 3 factors are indicative of poor cerebrovascular reserve, a parameter that may be evaluated using advanced imaging such as CT perfusion scanning (Figs. 1 and 2), SPECT, perfusion-weighted MR imaging, and dynamic susceptibility contrast MR imaging. $., 13,40 \mathrm{Kaku}$ et al..$^{13}$ retrospectively analyzed the results obtained in 30 patients who underwent CA angioplasty and stent placement. All patients underwent preoperative assessment of cerebrovascular reactivity by way of an acetazolamide challenge using SPECT. Cerebrovascular reactivity was calculated as the $\mathrm{CBF}$ during the acetazolamide challenge minus the resting $\mathrm{CBF}$ divided by the resting $\mathrm{CBF}$. Those with a cerebrovascular reactivity of $<20 \%$ were more likely to develop hyperperfusion following the procedure. This strategy may allow the identification of individuals in whom incremental revascularization would be preferred. Such patients may benefit from serial procedures with initial underinflation to permit the vascular territory sufficient opportunity to regain the ability to autoregulate, the same idea advocated by Spetzler et al. ${ }^{34}$ in their early description.

Prophylaxis. As an alternative to these advanced imaging techniques, some writers have advocated the uniform initiation of strict blood pressure control in the early postprocedure period. Abou-Chebl and colleagues ${ }^{1}$ aggressively managed the blood pressure in 570 patients following CAS, and compared data acquired in these 570 patients with those in 266 patients treated prior to the institution of the protocol. Patients who were hypertensive at baseline had their home medications restarted, with those needing additional control receiving oral metoprolol and intravenous nitroglycerin as necessary. Additionally, patients were stratified based on their risk factors, with those having hypertension, $\geq 90 \%$ stenosis, and/or $\geq 80 \%$ contralateral CA stenosis, being held to $<120 / 80 \mathrm{~mm} \mathrm{Hg}$ as opposed to $140 / 90 \mathrm{~mm} \mathrm{Hg}$ for all others. This resulted in a nonsignificant decrease in the incidence of all HPS from 1.9 to $0.5 \%$, and a significant decrease in the rate of ICH from 1.1 to $0 \%(p=0.032)$. More remarkable results were obtained in the high-risk population, with the rate of HPS decreasing from 29.4 to $4.2 \%(p=0.006)$. While

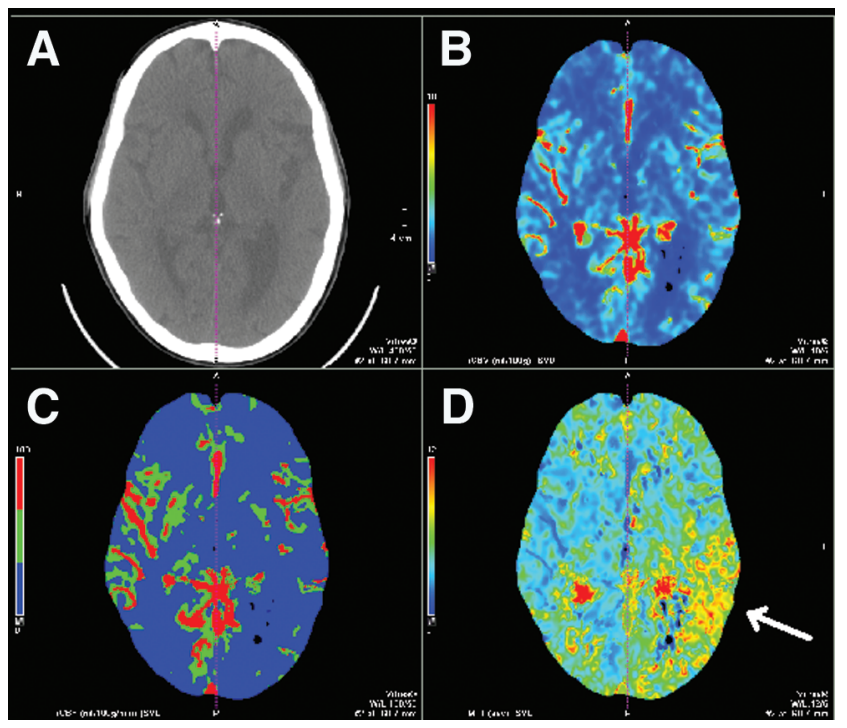

Fig. 1. Preprocedural CT perfusion scans (reference slice $[A]$, cerebral blood volume $[\mathrm{B}], \mathrm{CBF}[\mathrm{C}]$, and mean transit time [D]) demonstrating an increase in mean transit time in the posterior aspect of the left middle cerebral artery (MCA) territory coupled with a decrease in CBF. 


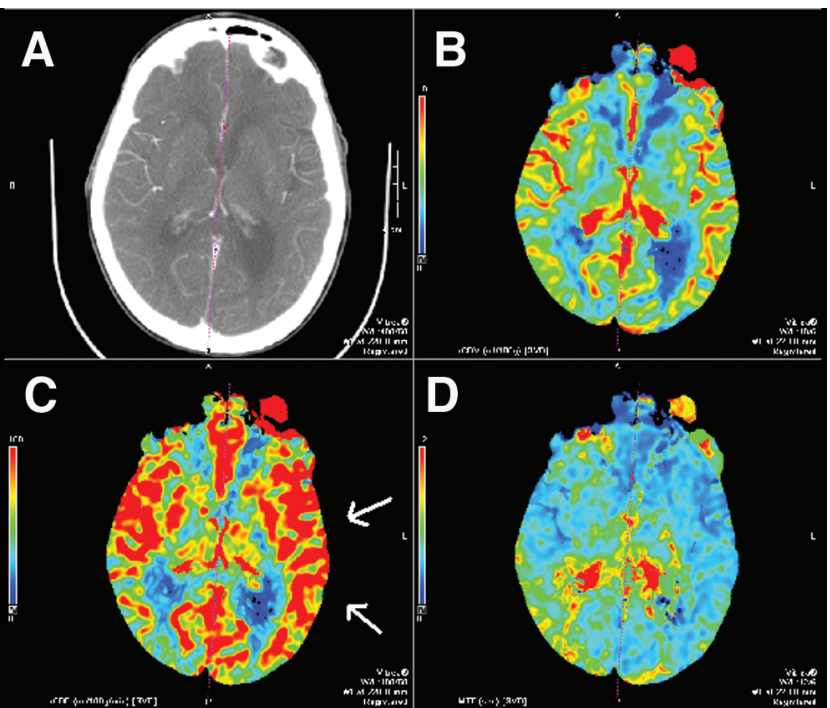

Fig. 2. Posttreatment CT perfusion images obtained after revascularization of the left internal carotid artery and left MCA, demonstrating a significant increase in the cerebral blood volume and CBF, consistent with hyperperfusion. Additionally, there is resolution of the previously noted alteration in mean transit time.

these results are suggestive, they have not been consistently demonstrated, as evidenced by the review of Ogasawara et al. ${ }^{27}$ in which poor postoperative blood pressure control was not significantly associated with a decrease in the incidence of hyperperfusion following CAS. Nevertheless, most clinicians believe that the benefits substantially outweigh the risks, and therefore this strategy is routinely practiced at our institution.

Other interventions aimed at decreasing the incidence of HPS include the use of free radical scavengers such as edaravone. Edaravone inhibits lipid peroxidation, thereby preventing endothelial injury, ${ }^{40}$ and recent evaluation of its use in the setting of acute stroke has demonstrated a significant improvement in functional outcomes as assessed by the modified Rankin Scale. ${ }^{8}$ Ogasawara and colleagues ${ }^{26}$ pretreated patients undergoing CEA with the compound and observed a significant reduction in the incidence of HPS ( 2 vs $16 \%, \mathrm{p}=0.0310$ ); however, its evaluation in the setting of endovascular intervention has been limited.

Therapy. Following symptomatic presentation, therapeutic measures must focus on preventing further progression and on imaging performed to evaluate for cerebral edema or hemorrhage. Primary interventions include aggressive titration of blood pressure to a systolic value of $<120-140 \mathrm{~mm} \mathrm{Hg}^{2}$ and initiation of an anticonvulsant regimen in the setting of seizures (prophylactic use is not indicated).$^{40}$ Substantial evidence does not exist regarding the agent of choice for blood pressure control; however, drugs such as nitroprusside, whose mechanism of action is vasodilation, should be avoided so as not to increase CBF. Should cerebral edema progress such that significant increases in intracranial pressure occur, one should institute control in an orderly fashion using sedation, osmotic agents (mannitol and hypertonic saline), and paralysis if necessary. Nevertheless, it cannot be overemphasized that prevention remains the primary objective, as the presence of severe HPS heralds mortality and long-term morbidity rates of up to 50 and $30 \%$, respectively. ${ }^{40}$

Timing. The question of the ideal timing of intervention following an acute event is another considerable concern with regard to the development of HPS. Classically, operative intervention has been considered to increase the risk if it is performed within 3-4 weeks following an ischemic event. ${ }^{3}$ However, a recent analysis of the data from the European Carotid Surgery Trial and the North American Symptomatic Carotid Endarterectomy Trial revealed that the greatest benefit was achieved in patients randomized within 2 weeks of their last ischemic event. ${ }^{31}$ Other authors have more specifically addressed endovascular intervention with similar conclusions. ${ }^{11,22,42}$ Zaidat et al. ${ }^{42}$ reviewed the outcomes in 38 patients undergoing CA angioplasty and stenting within a mean of 55 hours following acute ischemic stroke. Three patients $(7.7 \%)$ developed worsening neurological deficits, with 2 suffering from further minor stroke and 1 from abciximab-related ICH. Hyperperfusion syndrome did not occur in any patient. The authors concluded that in those with small infarct volumes $\left(\leq 10-12 \mathrm{~cm}^{3}\right)$ and mild to moderate neurological deficits (National Institutes of Health Stroke Scale score $\leq 8$ ), early revascularization was safe if deemed clinically necessary.

\section{Conclusions}

The use of endovascular cerebral revascularization will continue to increase, especially in cases of intracranial lesions for which there exist limited therapeautic options. Although HPS has been characterized following CEA, there is sparse evidence regarding its occurrence after percutaneous intervention. Clearly there is some underlying variation in the pathophysiology, as the time course and incidence of HPS are not identical between the 2 groups. To date, aggressive blood pressure management is the most commonly instituted prophylactic measure, but even this does not have consistent support. New treatments such as edaravone hold promise for the prevention of HPS, with further evidentiary support pending. Future research must focus on evaluating the hemodynamic variations following angioplasty and stent placement, especially those that involve smaller vascular territories as seen in middle cerebral artery and posterior circulation revascularization. Precise characterization of the specific risk factors, including timing of intervention, and how they relate to the individual procedures, will allow clinicians to more appropriately guide patient care.

\section{Disclaimer}

The authors report no conflict of interest concerning the materials or methods used in this study or the findings specified in this paper.

\section{References}

1. Abou-Chebl A, Reginelli J, Bajzer CT, Yadav JS: Intensive treatment of hypertension decreases the risk of hyperperfusion and intracerebral hemorrhage following carotid artery stenting. Catheter Cardiovasc Interv 69:690-696, 2007 


\section{Hyperperfusion syndrome after endovascular revascularization}

2. Abou-Chebl A, Yadav JS, Reginelli JP, Bajzer C, Bhatt D, Krieger DW: Intracranial hemorrhage and hyperperfusion syndrome following carotid artery stenting: risk factors, prevention, and treatment. J Am Coll Cardiol 43:1596-1601, 2004

3. Bernstein M, Fleming JF, Deck JH: Cerebral hyperperfusion after carotid endarterectomy: a cause of cerebral hemorrhage. Neurosurgery 15:50-56, 1984

4. Buhk JH, Cepek L, Knauth M: Hyperacute intracerebral hemorrhage complicating carotid stenting should be distinguished from hyperperfusion syndrome. AJNR Am J Neuroradiol 27:1508-1513, 2006

5. Chimowitz MI, Lynn MJ, Howlett-Smith H, Stern BJ, Hertzberg VS, Frankel MR, et al: Comparison of warfarin and aspirin for symptomatic intracranial arterial stenosis. N Engl J Med 352:1305-1316, 2005

6. Coutts SB, Hill MD, Hu WY: Hyperperfusion syndrome: toward a stricter definition. Neurosurgery 53:1053-1060, 2003

7. Crowley RW, Medel R, Dumont AS: Evolution of cerebral revascularization techniques. Neurosurg Focus 24(2): E3, 2008

8. Edaravone Acute Infarction Study Group: Effect of a novel free radical scavenger, edaravone (MCI-186), on acute brain infarction. Randomized, placebo-controlled, double-blind study at multicenters. Cerebrovasc Dis 15:222-229, 2003

9. Fukuda T, Ogasawara K, Kobayashi M, Komoribayashi N, Endo H, Inoue T, et al: Prediction of cerebral hyperperfusion after carotid endarterectomy using cerebral blood volume measured by perfusion-weighted MR imaging compared with single-photon emission CT. AJNR Am J Neuroradiol 28:737-742, 2007

10. Geevasinga N, Morris JGL, Ross DL: Carotid stenting and cerebral hyperperfusion syndrome. J Clin Neurosci 15:301305,2008

11. Geisler BS, Rother J, Kucinski T, Zeumer H, Eckert B: Emergency carotid artery stenting in persistent hemodynamic deficit associated with severe carotid stenosis. AJNR Am J Neuroradiol 26:549-552, 2005

12. Gurm HS, Yadav JS, Fayad P, Katzen BT, Mishkel GJ, Bajwa TK, et al: Long-term results of carotid stenting versus endarterectomy in high-risk patients. N Engl J Med 358:15721579,2008

13. Kaku Y, Yoshimura SI, Kokuzawa J: Factors predictive of cerebral hyperperfusion after carotid angioplasty and stent placement. AJNR Am J Neuroradiol 25:1403-1408, 2004

14. Kasner SE, Chimowitz MI, Lynn MJ, Howlett-Smith H, Stern BJ, Hertzberg VS, et al: Predictors of ischemic stroke in the territory of a symptomatic intracranial arterial stenosis. Circulation 113:555-563, 2006

15. Komotar RJ, Wilson DA, Mocco J, Jones JE, Connolly ES Jr, Lavine SD, et al: Natural history of intracranial atherosclerosis: a critical review. Neurosurgery 58:595-601, 2006

16. Kulik T, Kusano Y, Aronhime S, Sandler AL, Winn HR: Regulation of cerebral vasculature in normal and ischemic brain. Neuropharmacology 55:281-288, 2008

17. Liu AY, Do HM, Albers GW, Lopez JR, Steinberg GK, Marks MP: Hyperperfusion syndrome with hemorrhage after angioplasty for middle cerebral artery stenosis. AJNR Am J Neuroradiol 22:1597-1601, 2001

18. McCabe DJ, Brown MM, Clifton A: Fatal cerebral reperfusion hemorrhage after carotid stenting. Stroke 30:2483-2486, 1999

19. McKevitt FM, Sivaguru A, Venables GS, Cleveland TJ, Gaines PA, Beard JD, et al: Effect of treatment of carotid artery stenosis on blood pressure: a comparison of hemodynamic disturbances after carotid endarterectomy and endovascular treatment. Stroke 34:2576-2581, 2003
20. Meyers PM, Higashida RT, Phatouros CC, Malek AM, Lempert TE, Dowd CF, et al: Cerebral hyperperfusion syndrome after percutaneous transluminal stenting of the craniocervical arteries. Neurosurgery 47:335-345, 2000

21. Meyers PM, Phatouros CC, Higashida RT: Hyperperfusion syndrome after intracranial angioplasty and stent placement. Stroke 37:2210-2211, 2006

22. Miyamoto N, Naito I, Takatama S, Shimizu T, Iwai T, Shimaguchi $\mathrm{H}$ : Urgent stenting for patients with acute stroke due to atherosclerotic occlusive lesions of the cervical internal carotid artery. Neurol Med Chir (Tokyo) 48:49-56, 2008

23. Morrish W, Grahovac S, Douen A, Cheung G, Hu W, Farb R, et al: Intracranial hemorrhage after stenting and angioplasty of extracranial carotid stenosis. AJNR Am J Neuroradiol 21:1911-1916, 2000

24. Niesen W-D, Rosenkranz M, Eckert B, Meissner M, Weiller C, Sliwka U: Hemodynamic changes of the cerebral circulation after stent-protected carotid angioplasty. AJNR Am J Neuroradiol 25:1162-1167, 2004

25. Nikolsky E, Patil CV, Beyar R: Ipsilateral intracerebral hemorrhage following carotid stent-assisted angioplasty: a manifestation of hyperperfusion syndrome: a case report. Angiology 53:217-223, 2002

26. Ogasawara K, Inoue T, Kobayashi M, Endo H, Fukuda T, Ogawa A: Pretreatment with the free radical scavenger edaravone prevents cerebral hyperperfusion after carotid endarterectomy. Neurosurgery 55:1060-1067, 2004

27. Ogasawara K, Sakai N, Kuroiwa T, Hosoda K, Iihara K, Toyoda K, et al: Intracranial hemorrhage associated with cerebral hyperperfusion syndrome following carotid endarterectomy and carotid artery stenting: retrospective review of 4494 patients. J Neurosurg 107:1130-1136, 2007

28. Phatouros CC, Meyers PM, Higashida RT, Malek AM, Lempert TE, Dowd CF, et al: Intracranial hemorrhage and cerebral hyperperfusion syndrome after extracranial carotid artery angioplasty and stent placement. AJNR Am J Neuroradiol 23:503-504, 2002

29. Pilz G, Klos M, Bernhardt P, Schone A, Scheck R, Hofling $B$ : Reversible cerebral hyperperfusion syndrome after stenting of the carotid artery - two case reports. Clin Res Cardiol 95:186-191, 2006

30. Rezende MT, Spelle L, Mounayer C, Piotin M, Abud DG, Moret J: Hyperperfusion syndrome after stenting for intracranial vertebral stenosis. Stroke 37:e12-e14, 2006

31. Rothwell PM, Eliasziw M, Gutnikov SA, Warlow CP, Barnett HJM: Endarterectomy for symptomatic carotid stenosis in relation to clinical subgroups and timing of surgery. Lancet 363:915-924, 2004

32. Sanchez-Arjona MB, Sanz-Fernandez G, Franco-Macias E, Gil-Peralta A: Cerebral hemodynamic changes after carotid angioplasty and stenting. AJNR Am J Neuroradiol 28:640644, 2007

33. Schoser BG, Heesen C, Eckert B, Thie A: Cerebral hyperperfusion injury after percutaneous transluminal angioplasty of extracranial arteries. J Neurol 244:101-104, 1997

34. Spetzler RF, Wilson CB, Weinstein P, Mehdorn M, Townsend J, Telles D: Normal perfusion pressure breakthrough theory. Clin Neurosurg 25:651-672, 1978

35. Suga Y, Ogasawara K, Saito H, Komoribayashi N, Kobayashi M, Inoue T, et al: Preoperative cerebral hemodynamic impairment and reactive oxygen species produced during carotid endarterectomy correlate with development of postoperative cerebral hyperperfusion. Stroke 38:2712-2717, 2007

36. Sundt TM Jr, Sharbrough FW, Piepgras DG, Kearns TP, Messick JM Jr, O'Fallon WM: Correlation of cerebral blood flow and electroencephalographic changes during carotid endarterectomy: with results of surgery and hemodynamics of cerebral ischemia. Mayo Clin Proc 56:533-543, 1981

37. Sundt TM Jr, Smith HC, Campbell JK, Vlietstra RE, Cucchi- 


\section{R. Medel, R. W. Crowley, and A. S. Dumont}

ara RF, Stanson AW: Transluminal angioplasty for basilar artery stenosis. Mayo Clin Proc 55:673-680, 1980

38. Takayama K, Nakagawa H, Iwasaki S, Taoka T, Wada T, Myouchin $\mathrm{K}$, et al: Cerebral hemorrhage with angiographic extravasation immediately after carotid artery stenting. Radiat Med 25:359-363, 2007

39. Terada $T$, Tsuura $M$, Matsumoto $H$, Masuo $O$, Tsumoto $T$, Yamaga $\mathrm{H}$, et al: Hemorrhagic complications after endovascular therapy for atherosclerotic intracranial arterial stenoses. Neurosurgery 59:310-318, 2006

40. van Mook WN, Rennenberg RJ, Schurink GW, van Oostenbrugge RJ, Mess WH, Hofman PA, et al: Cerebral hyperperfusion syndrome. Lancet Neurol 4:877-888, 2005

41. Yadav JS, Wholey MH, Kuntz RE, Fayad P, Katzen BT, Mishkel GJ, et al: Protected carotid-artery stenting versus endarterectomy in high-risk patients. N Engl J Med 351:14931501,2004
42. Zaidat OO, Alexander MJ, Suarez JI, Tarr RW, Selman WR, Enterline DS, et al: Early carotid artery stenting and angioplasty in patients with acute ischemic stroke. Neurosurgery 55:1237-1243, 2004

43. Zhang R, Zhou G, Xu G, Liu X: Posterior circulation hyperperfusion syndrome after bilateral vertebral artery intracranial stenting: case report. Ann Vasc Surg [epub ahead of print], 2008

Manuscript submitted November 15, 2008.

Accepted January 15, 2009.

Address correspondence to: Aaron S. Dumont, M.D., Department of Neurological Surgery, University of Virginia System, Box 800212, Charlottesville, Virginia 22908. email: bjb4k@virginia.edu. 